\title{
The COVID-19 pandemic underscores the need for an equity-focused global health agenda
}

N. Jensen (1) ${ }^{1 凶}, A . H$. Kelly (i) ${ }^{1} \&$ M. Avendano ${ }^{1}$

Over the past few months, COVID-19 has ravaged health systems and economies in countries across the world. While many would argue that a pandemic of respiratory disease was predictable, the systematic failures of the response came as a surprise. From the shortage of hospital beds and medical equipment to the gross insufficiencies in national surveillance systems, supply chains and laboratory capacity, COVID-19 has laid bare the health care limitations that 'global north' and 'global south' share. A stark set of differences, however, run across the parallels in our collective predicament: indeed, what has become ever-more apparent is the radically uneven distribution of the health, social and economic risks associated with the pandemic-and the public health measures implemented in response-both within and between societies. As concerns grow over a prolonged period of COVID-19 waves, further insights are needed into who bears the largest share of COVID-19 burden and why. The pursuit of health equity is widely held to be global health's raison d'être; and yet, the deep inequities laid bare by the current pandemic underscore that the field must do more and we must do better. This article identifies five key domains for equity research and action going forward. These 'equity frontiers' are not meant to be exhaustive. Rather our emphasis here is on drawing lessons from the COVID-19 pandemic as a prompt for a revived-if not rethought-equity agenda for an evolving global health field. 


\section{COVID-19 as a magnifier of health inequalities}

ive months into the pandemic, we are faced with an evergrowing evidence base on how the COVID-19 pandemic not only exposes but exacerbates existing health disparities and their underlying social determinants. Early data from China showed the disproportionate vulnerability to the virus for older people and individuals with pre-existing health conditions (Guan et al., 2020). As the pandemic evolved, perhaps the most striking finding has been the disproportionally high infection and mortality rates among people from Black and Minority Ethnic (BAME) backgrounds in the UK (Public Health England, 2020) and among African Americans (CDC, 2020). The impact of the pandemic is also clearly gendered: although men generally appear more vulnerable to COVID-19 infection, women make up the majority of the global health workforce at increased risk of hospital infection (Wenham et al., 2020).

Such findings have prompted wide-spread calls for the routine disaggregation of COVID-19 case and fatality data by age, gender, ethnicity and other social stratifiers (Khunti et al., 2020; Dowd et al., 2020). But although improvements in data are clearly necessary, this paper argues that a more nuanced epidemiological analysis can only be the beginning of a longer-term agenda of equity research and intervention. Scrutiny of the overt and the perhaps more insidious ways that the COVID-19 pandemic maps onto existing health inequities is clearly needed and should be used to underscore the need to address the structural conditions at their root.

An equity-focused COVID-19 agenda. What would an equity approach that goes beyond disaggregated statistics look like? While this is a long-term agenda, we propose, as a starting point, to pursue five frontiers of enquiry and action focussing on: the social determinants, unequal effect of public health measures, fragile systems, inequities within systems, and the politics of global health attention and neglect.

Social determinants of health in the context of COVID-19. In 2008, the World Health Organization's (WHO) Commission on Social Determinants of Health (CSDH, 2008) successfully made the case that achieving health equity requires both: mapping how (ill-) health is distributed among different social groups, and showing how this distribution reflects the unequal "conditions in which people are born, grow, live, work, and age" (CSDH, 2008, p. 1).

In the current crisis, more granular epidemiological data is clearly necessary to document COVID-19 disease burdens among socially disadvantaged groups. The rigorous compilation of disaggregated global, national and regional infection rates and deaths would allow a systematic assessment of which populations are more susceptible to infection, experience the worst outcomes, and are most likely to die from the disease. At the very least, this should involve the routine collection of a standardised set of metrics, such as those included in the WHO-endorsed PROGRESS 'equity lens'-place of residence, race or ethnicity, occupation, gender, religion, education, socioeconomic status, social capital or status (WHO, 2013). In addition, more data is needed on how COVID-19 prognosis is impacted by pre-existing conditions, including not only non-communicable diseases but also undernutrition, HIV/Aids, TBC and malaria (Nkengasong and Mankula, 2020).

But beyond these informative, yet arguably quite narrow, social categories, an equity lens should also be broadened to expose how a wider range of factors-including racism, colonialism, sexism, classism, ageism, ableism, homophobia and transphobia-make some population groups more vulnerable in the face of COVID19. There is now a robust body of evidence that socio-economic disadvantage, gender and class inequities and racism are among the 'fundamental causes' (Phelan and Link, 2015) of health and disease. Building on this, epidemiological analyses must be complemented by in-depth qualitative research to show how diverse forms of inequality intersect and become 'embodied' (Krieger, 2015; Nguyen and Pechard, 2003) in the context of this current pandemic.

Crucially, analyses of the differential distribution of vulnerability and risk must go hand in hand with a diagnosis of the wider political, institutional, and economic conditions that allow health inequalities to persist and be re-produced through COVID-19. The social determinants model has been successful in mainstreaming attention to the 'causes of the causes' of illhealth, such as poverty. And yet, many have argued that it does not go far enough in shifting the analytical focus from individual or group-level risk factors to the political-economic systems that differently distribute power and resources (Navarro, 2009; Krieger et al., 2010). Alternative proposals have emerged, for example, from Latin America, where scholars are spearheading approaches that foreground theoretically informed analyses of the dynamic processes of 'social determinations' that underlie health inequalities (Breilh, 2008; Spiegel et al., 2015). As the role of existing forms of marginalisation and disparity in shaping the COVID-19 pandemic becomes clear, the 'social determinations' framework may be useful to spotlight how the distribution of (Covid-19) health risks and vulnerabilities is shaped by political decisions, such as, for example, the dismantling of public health systems and services under neoliberalism and, most recently, austerity policies (Nunes, 2020; see below). Conversely, it may also encourage scholars to engage with and learn from the existing and new forms of solidarity, collectivity and care that have been mobilised by the pandemic everywhere (Sitrin and Colectiva Sembrar, 2020) to open up new conceptual and practical pathways to think and do equity.

A key example of the need to further unpack our categories of quantitative analysis is the way age has featured as a measure of COVID-19 risk over recent months. Due to children's reported underrepresentation among severe Covid-19 cases, the early stages of the pandemic were dominated by a focus on children as 'transmission links'-as key nodes in epidemiological networks that could be targeted by public health measures in order to protect older populations perceived to be more vulnerable to serious forms of the disease (Kelvin and Halperin, 2020). While subsequent studies seem to confirm statistically less severe Covid19 disease in children and young adults (Götzinger et al., 2020), they also highlight the enduring knowledge gaps in regard to more severe forms of disease and sequelae in children as well as their contribution to community transmission (ECDPC, 2020). At the same time, the potentially significant and long-lasting impact of public health measures on children's wellbeing and educational attainment have become a focus of heightened concern, pointing to how various and complex forms of inequalities are (re-)produced by confinement and distance learning (The WHO-UNICEF- Lancet Commissioners, 2020). That young people, and more so already vulnerable young people, are likely to bear significant long-term impacts of the pandemic highlights the need for an equity agenda that scrutinises both (but separately): the specific risk factors for COVID-19 disease and the wider determinants that play a role in the distribution of health risks and vulnerabilities in the context of the pandemic. An equity agenda must, therefore, extend beyond an analysis of determinants of COVID-19 disease to scrutinise the short and long-term effects of public health measures implemented in response. 
The unequal effect of public health measures. The gradual yet uneven (United Nations, 2020) reopening of schools this Autumn has spotlighted the significant and likely lasting impact of the Covid-19 pandemic on children. And yet, it is only the latest of a series of examples that show why analyses of inequalities in terms of COVID-19-related health outcomes and access to care must be complemented by scrutiny of the unequal effects of public health measures adopted to contain the pandemic.

Across the world, countries have put in place measures to prevent COVID-19 infection and mitigate transmission, ranging from stringent 'test, trace and isolate' strategies in countries such as South Korea to countrywide 'lockdowns' in most of Europe, India and some Latin American and African countries. The ultimate public health worth and political wisdom of strict social distancing measures in reducing COVID-19 transmission remains an open question. Selective national and local responses such as in New Zealand, Uruguay and the Indian state of Kerala have been widely held up as exemplary for combining swiftly implemented social distancing measures and rigorous track, trace and isolate programmes with supportive economic measures and effective community engagement and communication strategies (Baker et al., 2020; Werner and Lammertyn, 2020; Menon et al., 2020). In contrast, other countries have been lauded for the effectiveness of their stringent public health measures, but those impositions clearly came at a great cost. One example is Sri Lanka, where the government's swift and decisive Covid-19 response has been overshadowed by accusations of discriminatory measures against the country's Muslim population and concerns over a significant economic fallout (Al Jazeera, 2020).

As lockdowns are loosened and case numbers in many countries rebound, governments across the world are facing difficult decisions to implement appropriate combinations of measures to deal with likely future 'waves' of infection. But despite that uncertainty, what has become abundantly clear is that public health advice is far more difficult to follow for some than it is for others. This includes large parts of populations worldwide that live in, as a group of leading African academics and writers have referred to, 'conditions of chronic precarity' (African Arguments, 2020), whose everyday realities seem to have been summarily excluded from public health policy consideration.

But even as large-scale lockdowns in many countries are starting to ease, the continuous deployment of such mitigation measures in a more geographically targeted fashion will provide new insights into the unequal distribution of risk. One key example is the recent COVID-19 outbreak and subsequent localised lockdown linked to meat processing plants in Germany, which has spotlighted the exploitative working and living conditions of affected staff, predominantly low-paid seasonal workers from Eastern Europe (Die Zeit, 2016).

Equity experts have long argued that health interventions may inadvertently worsen health inequities unless they are specifically aimed at improving the health of those worse-off (Gwatkin and Ergo, 2011). The COVID-19 pandemic acutely demonstrates that the same holds true for public health measures designed and implemented without consideration of their possible differential impact on different population groups. An equity-focused COVID-19 approach must therefore document the mid-term and long-term differential impact of lockdown and other public health measures and evidence the disparity in their effectiveness and unintended consequences for health and socioeconomic wellbeing. But more so, it will need to expose the root causes that create and sustain social disadvantage and scrutinise the mechanisms through which such disadvantage is articulated and reinforced, including at the level of medical and public health infrastructures.
The disproportionate impact of fragile health and social benefit systems on disadvantaged groups. As much as the pandemic points to the dangers of imposing 'one-size-fits-all' public health approaches in vastly different contexts (Mehtar et al., 2020; Cash and Patel, 2020), it also highlights that no rapidly implemented emergency response mechanism can offset the structural fragilities of healthcare and social welfare benefit systems caused by decades of underinvestment and neglect.

That well-functioning healthcare systems are key to achieving health equity has become a truism in high-level global health debates, consolidated over the past two decades around the push for Health System Strengthening (HSS). Within these discussions, poorer countries' health systems tend to be portrayed as 'bottlenecks' to the delivery of evidence-based healthcare services. To many, the calamitous effects COVID-19 on 'weak' health systems, especially in Africa, seemed inevitable.

In many African nations Covid-19 has indeed exposed severe constraints in terms of testing and surveillance capacities, numbers of health workers, Personal Protective Equipment (PPE) stockpiles, intensive care unit (ICU) beds, ventilation systems and constrained health budgets to scale up outbreak responses (Nkengasong and Mankoula, 2020). The clarity with which those limitations have been brought into view have the potential to springboard internationally supported HSS efforts to the forefront of global health policy. In some key ways, however, the pandemic has also exposed the ways in which the current HSS agenda falls short.

First, the breadth of country responses to the pandemic has highlighted examples of less-resourced countries that have launched effective public health measures to mitigate the impact of COVID-19 on their often fragile health systems (Dalglish, 2020). But, conversely, the pandemic has also exposed that health and social care system constraints are by no means limited to poorer 'global south' countries. Governments across the world have struggled to robustly respond to growing infection rates with medical and public health infrastructures that have been weakened by years of underinvestment, reorganisation and fragmentation. This holds true, for example, for the US, where the outgoing administration stifled implementation of the 2010 Affordable Care Act (ACA), which many had hoped would alleviate glaring health disparities by improving healthcare access especially for ethnic minorities and socio-economically disadvantaged groups (Williams et al., 2016; van Dorn et al., 2020; Himmelstein and Woolhandler, 2020). In the UK and many continental European countries, a twin drive towards cost reduction and privatisation has hollowed out health systems over at least the past decade, with indications that it is the health of poor and marginalised populations that has suffered most as a result (Karanikolos et al., 2013; Stuckler et al., 2017; McCoy, 2020).

Second, the current pandemic has revealed that health systems are rarely 'weak' in isolation. As the International Labour Organization (ILO) notes, the COVID-19 pandemic has "revealed the cracks in social protection systems" (ILO, 2020). Indeed, despite improvements over the past decade, across many African countries, for example, coverage of social protection systems remains low, which risked rendering social distancing measures ineffective (Ebuenyi, 2020). But in many European countries, too, reduced or stagnating healthcare funding in the wake of the 2007-2008 financial crisis has often accompanied wider programmes of public sector cuts with often significant indirect health impacts: determinants of health such as unemployment, homelessness, food insecurity and mental health issues increased across many European countries linked to reduced government spending; at the same time that social protection programmes 
that may mitigate their impact on health were often scaled back (Thomson et al., 2015; Stuckler et al., 2017).

An acknowledgement that past policies have served to create global inequities and stifled countries' ability to respond to public health emergencies must be the first step towards transforming not just health but also social security systems. More so, it should make clear that the strive for health equity cannot be divorced from a wider agenda for social, economic and political justice. That comprehensive political commitment was central to the 1978 Alma Ata Declaration but has since been progressively watered down, including by the HSS agenda where this is used to promote a narrow path towards health equity via the provision of healthcare alone.

An equity approach would reaffirm these commitments by calling for interventions into the social, economic and political conditions that (re-)create inequities. As part of this, more clearly needs to be done to acknowledge and address those forms of injustice and oppression that are embedded within and articulated through sectors and institutions of public life, including those related to health and healthcare.

Inequities within systems. Another important insight that will have to guide an equity approach is that inequities are not just the result of what happens when systems 'fail'. Rather, inequities are often the result of-and are refracted through - the way systems are set up and operate.

Across the world, healthcare workers-as well as carers, social workers, clinical support and lab workers, administrators and receptionists, cleaners, caterers and drivers, but also shopkeepers, delivery drivers, refuse collectors, etc.- -have played a crucial role in sustaining countries' critical infrastructures. Politicians and the media were quick to elevate these workers to national 'heroes' in the public consciousness. But what these laudations mask is the risks to which certain groups have been put not only by the nature of their work but also by the lack of adequate workplace protections. In the early months of the pandemic, much attention was on the wide-spread lack of PPE for healthcare and other 'essential' workers. But in many countries this could be said to be indicative of much deeper systemic failures as many essential workers also earn salaries below the median national income (Butcher, 2020); have been at the receiving end of wide-ranging public sector cuts (Mason and Asthana, 2017); become targets of increasingly repressive immigration systems (Goodfellow, 2020), and have been at the heart of what Cooper and Waldby (2014) refer to as the systematic outsourcing of risk associated with neoliberal and welfare reforms associated with 'post-Fordist' labour regimes. An equity-oriented COVID-19 agenda therefore must expose and address the inequalities that are 'baked into' and perpetuated by health systems and other 'essential' infrastructures.

It is of course well established that systemic forms of oppression, such as racism, become operable through discriminatory practices and policies at the level of institutions (Bailey et al., 2017; Jones, 2002). How institutions' policies and practices have reinforced health inequities and contributed to the differential effects of the COVID-19 pandemic on different population groups will have to scrutinised. And so do other ways that structural violence is exerted through the system: racism, classism, sexism and ableism - to name just a few of the many prevalent forms of oppression-also operate at the level of health system institutions themselves, such as through discriminatory recruitment and promotion processes, or are indeed embedded within biomedical technologies and public health programmes (Benjamin, 2016; Gentleman and Campbell, 2020; Neilson, 2020).

What this highlights is that health equity cannot be achieved by 'strengthening' healthcare institutions and systems alone with the aim to ensure everyone has access to care (although, again, this is crucially important). But we also need to address how health technologies, programmes, institutions and systems themselves are all-too-often suffused and shaped by the very forms of oppression and privilege that are at the root of health inequities. Put simply, health equity cannot be treated as the end point, but rather must be a commitment that infuses and guides every-day individual, institutional and societal action, in the healthcare sector and beyond.

The politics of global health attention/neglect. A final key dimension of an equity-focused agenda is what might be called the politics of global health attention and neglect, and its impact on shaping the pandemic. As others (Farmer, 1996; Nunes, 2016) have pointed out, the sense of urgency that results from pathogens being deemed global security threats may spur new visibility, funds and institutional arrangements; framing a situation as a crisis may also, however, foreclose a more careful attention to the social, economic, environmental and political milieu in which disease outbreaks occur as well as what responses could bebeyond immediate disease containment.

As Paul Farmer has noted, "the historical regard has shown us that what was not examined during an epidemic is often as important as what was" (Farmer, 1996, p. 267). Even as the COVID-19 pandemic is ongoing, an equity agenda would imply insisting on the importance of treating structural (health) inequalities as determining factors that shape the emergence and course of the pandemic, and that should frame a long-term response that goes beyond surveillance, transmission reduction and improved emergency preparedness.

How a focus on pandemic response diverts attention from other (health) issues should also be scrutinised. There are already numerous warning signs that must make this a priority concern. In the UK, the pandemic has significantly impacted patients' access to routine care (Reuters, 2020), with similar concerns raised across the world (Abajobir, 2020; Pai, 2020; Pramesh and Badwe, 2020; Rosenbaum, 2020; Wang et al., 2020; WHO, 2020a). In terms of malaria, for example, the WHO warns that disruptions to existing prevention campaigns and treatment programmes could result in a doubling of annual deaths rates (WHO, 2020b). An equity approach thus needs to eschew the temptation to treat the COVID-19 outbreak as a single-disease issue and keep a spotlight on the pandemic's effects on the prevention and treatment of other non-COVID-19-related conditions. Pre-existing chronic conditions, often themselves linked to social determinants, do not only exacerbate the risk of COVID-19 infection. But the pandemic may also exacerbate inequalities in chronic diseases both within and between countries: for example, as resources are diverted to outbreak control this is likely to disproportionately affect populations groups who already are higher risk and/or struggle to access healthcare services (Okereke et al., 2020), including mental health services (Rose et al., 2020). Keeping track of the multifarious effects of COVID-19 is crucial for improving outbreak response in the future, whether it is directed for future waves of COVID-19 or other yet unknown pathogens. To avoid the same devastating and differential outcomes, long-term and sustainable changes must be addressed across the spectrum of health needs.

Lastly, the politics of attention and neglect also speak to asymmetries in resources and power that pattern the global health field itself. Equity has long been fronted as the cornerstone of the field (Koplan et al., 2009); and yet, for too long this has been pursued through policies and programmes that privilege shortterm healthcare-focused interventions at the expense of a sustained focus on addressing the roots of social and health inequities and, as Birn and Nervi (2019, p. 7) put it, the "power 
relations that impede the fundamental changes needed to address these injustices". More so, ever-intensifying calls for the decolonisation of the way global health is both practiced and taught rightly call into question the ability of the field to address inequities when it mirrors and even perpetuates the very same injustices by framing efforts to improve international health as an ahistorical and apolitical enterprise and continuing to privilege certain knowledges, voices and bodies (Koris et al., 2020).

\section{Conclusion}

The five equity frontiers outlined here give but a glimpse of the many ways in which the COVID-19 pandemic intersects with and exacerbates social and health inequalities. If anything, the current pandemic has been a powerful reminder that health is much more than just a medical matter, as it is embedded within a complex set of social, economic and political determinants. Providing a comprehensive picture of the overlapping, durational and socially situated burden of the pandemic will thus require a multidisciplinary approach: next to epidemiological evidence that documents inequalities in outcomes and care, in depth qualitative and ethnographic research will be critical to evidence the heterogenous on-the-ground experiences and impacts of the pandemic, highlight the limitations and blindspots of one-size-fits-all pandemic responses, and point to the complex pathways through which imbalances in power and resources lead to health inequities.

The current crisis underscores why the pursuit of health equity should remain the top priority in global health. But it also lays bare the gap between the equity ambitions of the global health field and healthcare realities. The attention that the pandemic has brought to social and health inequalities may offer an opportunity to address that shortcoming. But, in so doing, it should also serve as a prompt to re-think the global health equity agenda and reclaim it is part of a much wider struggle for social, economic, political and epistemic justice.

Received: 3 July 2020; Accepted: 1 December 2020; Published online: 18 January 2021

\section{References}

Abajobir A (2020) Africa can't let maternity care slide during the coronavirus pandemic. The Conversation, April 21, 2020 [online]. http://theconversation. com/africa-cant-let-maternity-care-slide-during-the-coronavirus-pandemic136424. Accessed 24 Sep 2020

African Arguments (2020) COVID-19: an open letter from African intellectuals to Africa's leaders. April 162020 [online]. https://africanarguments.org/2020/ 04/16/coronavirus-open-letter-african-intellectuals-africa-leaders/. Accessed 16 Apr 2020

Al Jazeera (2020) Sri Lanka: economy, human rights key challenges facing Rajapaksas. Al Jazeera. Accessed August 18, 2020 [online]. https://www.aljazeera. com/news/2020/08/sri-lanka-economy-human-rights-key-challenges-facingrajapaksas-200818090240530.html. Accessed 20 Aug 2020

Baker MG, Wilson N, Anglemyer A (2020) Successful elimination of COVID-19 transmission in New Zealand. New Engl J Med e56. https://doi.org/10.1056/ NEJMc2025203

Bailey ZD, Krieger N, Agénor M, Graves J, Linos N, Bassett MT (2017) Structural racism and health inequities in the USA: evidence and interventions. Lancet 389(10077):1453-1463. https://doi.org/10.1016/S0140-6736(17)30569-X

Benjamin R (2016) Innovating inequity: if race is a technology, postracialism is the genius bar. Ethn Rac Stud 39(13):2227-2234. https://doi.org/10.1080/ 01419870.2016 .1202423

Birn AE, Nervi L (2019) What matters in health (care) universes: delusions, dilutions, and ways towards universal health justice. Glob Health 15(1):1-2. https://doi.org/10.1186/s12992-019-0521-7

Breilh J (2008) Latin American critical ('Social') epidemiology: new settings for an old dream. Int J Epidemiol 37(4):745-750. https://doi.org/10.1093/ije/dyn135

Butcher B (2020) What are key workers paid? BBC News, April 21, 2020 [online]. https://www.bbc.com/news/uk-52312038. Accessed 15 Jun 2020
Cash R, Patel V (2020) Has COVID-19 subverted global health? Lancet 395 (10238):1687-1688. https://doi.org/10.1016/S0140-6736(20)31089-8

CDC (2020) Coronavirus Disease 2019 (COVID-19) in the U.S. centers for disease control and prevention, April 20, 2020. https://www.cdc.gov/coronavirus/ 2019-ncov/cases-updates/cases-in-us.html. Accessed 15 Jun 2020

Cooper M, Waldby C (2014) Clinical labor: tissue donors and research subjects in the global bioeconomy. Duke University Press, Durham and London

$\mathrm{CSDH}$ (2008) Closing the gap in a generation: health equity through action on the social determinants of health. World Health Organization, Geneva

Dalglish SL (2020) COVID-19 gives the lie to global health expertise. Lancet 395 (10231):1189

Die Zeit (2016) Toennis-Corona-Ausbruch im Schlachtbtrieb. Die Zeit, June 19, 2020 [online]. https://www.zeit.de/thema/toennies. Accessed 19 June 2020

Dowd JB, Andriano L, Brazel DM, Rotondi V, Block P, Ding X, Liu Y, Mills MC (2020) Demographic science aids in understanding the spread and fatality rates of COVID-19. Proc Natl Acad Sci USA 117(18):9696-9698. https://doi. org/10.1073/pnas.2004911117

Ebuenyi ID (2020) COVID-19: an opportunity for African governments to rethink social welfare benefits and protection. Pan Afr Med J 35(2):64. https://doi. org/10.11604/pamj.supp.2020.35.2.23875

ECDPC (2020) COVID-19 in children and the role of school settings in COVID-19 transmission. European Centre for Disease Prevention and Control, Stockholm

Farmer P (1996) Social inequalities and emerging infectious diseases. Emerg Infect Dis 2(4):259-269

Gentleman A, Campbell D (2020) NHS blood unit systemically racist, internal report finds. Guardian June 9, 2020 [online]. https://www.theguardian.com/ society/2020/jun/09/nhs-blood-unit-systematically-racist-internal-reportfinds?CMP=Share_iOSApp_Other. Accessed 9 June 2020

Götzinger F, Santiago-García B, Noguera-Julián A, Lanaspa M, Lancella L, Carducci FI, Gabrovska N, Velizarova S, Prunk P, Osterman V, Krivec U (2020) COVID-19 in children and adolescents in Europe: a multinational, multicentre cohort study. Lancet Child Adolesc Health 4(9):653-661. https://doi. org/10.1016/S2352-4642(20)30177-2

Goodfellow M (2020) While 'low-skilled' migrants are saving us, the government is cracking down on them. Guardian, April 11, 2020 [online]. https://www. theguardian.com/commentisfree/2020/apr/11/low-skilled-migrantsgovernment-cracking-down. June 152020

Guan W, Ni Z, Hu Y, Liang W, Ou C, He J, Liu L et al. (2020) Clinical characteristics of coronavirus disease 2019 in China. New Engl J Med 382 (18):1708-1720. https://doi.org/10.1056/NEJMoa2002032

Gwatkin DR, Ergo A (2011) Universal health coverage: friend or foe of health equity? Lancet 9784(377):2160-2161. https://doi.org/10.1016/S0140-6736(10) 62058-2

Himmelstein DU, Woolhandler S (2020) The US health care system on the eve of the Covid-19 epidemic: a summary of recent evidence on its impaired performance. Int J Health Serv 50(4):408-414

ILO (2020) Policy Brief: COVID and the world of work: ensuring no one is left behind in the response and recovery. International Labour Organization, Geneva

Jones CP (2002) Confronting institutionalized racism. Phylon 50(1-2):7-22. https://doi.org/10.2307/4149999

Karanikolos M, Mladovsky P, Cylus J, Thomson S, Basu S, Stuckler D, Mackenbach JP, McKee M (2013) Financial crisis, austerity, and health in Europe. Lancet 381(9874):1323-1331. https://doi.org/10.1016/S0140-6736(13)60102-6

Kelvin AA, Halperin S (2020) COVID-19 in children: the link in the transmission chain. Lancet Infect Dis 20(6):633-634. https://doi.org/10.1016/S1473-3099 (20)30236-X

Khunti K, Singh AK, Pareek M, Hanif W (2020) Is ethnicity linked to incidence or outcomes of Covid-19? Br Med J 369:m1548. https://doi.org/10.1136/bmj. $\mathrm{m} 1548$

Koplan JP, Bond TC, Merson MH, Reddy KS, Rodriguez MH, Sewankambo NK, Wasserheit JN (2009) Towards a common definition of global health. Lancet 373(9679):1993-1995. https://doi.org/10.1016/S0140-6736(09)60332-9

Koris A, Mkumba L, Raveendran Y, Kenney C, Büyüm AK (2020) Beyond global health equity: the case for decolonizing global health. Medium, March 5, 2020 [online] August 22, 2020

Krieger N (2015) Proximal, distal, and the politics of causation: what's level got to do with it? Am J Public Health 98(2):221-230. https://doi.org/10.2105/ AJPH.2007.111278

Krieger N, Alegría M, Almeida-Filho N, da Silva JB, Barreto ML, Beckfield J, Berkman L, Birn AE, Duncan BB, Franco S, Garcia DA (2010) Who, and what, causes health inequities? Reflections on emerging debates from an exploratory Latin American/North American workshop. $\mathrm{Br}$ Med J 64 (9):747-749. https://doi.org/10.1136/jech.2009.106906

Mason R, Asthana A (2017) Damning government report shows depth of public sector pay cuts. Guardian, 3 July 2017 [online]. https://www.theguardian. 
com/society/2017/jul/03/damning-government-report-shows-scale-of-publicsector-pay-cuts. Accessed 3 July 2020

McCoy D (2020) Coronavirus has exposed the dangerous failings of NHS marketisation. The Guardian, 5 May 2020 [online]. https://www.theguardian. com/commentisfree/2020/may/05/coronavirus-nhs-marketisation-pandemic. Accessed 3 July 2020

Mehtar S, Preiser W, Aissatou Lakhe N, Bousso A, Muyembe TamFu JJ, Kalley O et al. (2020) Limiting the spread of COVID-19 in Africa: one size mitigation strategies do not fit all countries. Lancet Global Health 8(7):e881-e883. https://doi.org/10.1016/S2214-109X(20)30212-6

Menon JC, Rakesh PS, John D, Thachathodiyl R, Banerjee A (2020) What was right about Kerala's response to the COVID-19 pandemic? BMJ Global Health 5 (7):e003212. https://doi.org/10.1136/bmjgh-2020-003212

Navarro V (2009) What we mean by social determinants of health. Int J Health Serv 39(3):423-441. https://doi.org/10.2190/HS.39.3.a

Neilson S (2020) Ableism in the medical profession. Can Med Assoc J = J Assoc Med Can 192(15):E411-E412. https://doi.org/10.1503/cmaj.191597

Nguyen VK, Peschard K (2003) Anthropology, inequality, and disease: a review. Annu Rev Anthropol 32(1):447-74. https://doi.org/10.1146/annurev. anthro.32.061002.093412

Nkengasong JN, Mankoula W (2020) Looming threat of COVID-19 infection in Africa: act collectively, and fast. Lancet 395(10227):841-42. https://doi.org/ $10.1016 /$ S0140-6736(20)30464-5

Nunes J (2016) Ebola and the production of neglect in global health. Third World Q 37(3):542-556. https://doi.org/10.1080/01436597.2015.1124724

Nunes J (2020) The COVID-19 pandemic: securitization, neoliberal crisis, and global vulnerabilization. Cad Saúde Públ 36:e00063120. https://doi.org/ 10.1590/0102-311x00063120

Okereke M, Ukor NA, Adebisi YA, Ogunkola IO, Favour Iyagbaye E, Adiela Owhor G, Lucero-Prisno III DE (2020) Impact of COVID-19 on access to healthcare in low-and middle-income countries: current evidence and future recommendations. Int J Health Plan Manag 1-5. https://doi.org/10.1002/ hpm.3067

Pai M (2020) COVID-19 Coronavirus and tuberculosis: we need a damage control plan. Forbes, March 17, 2020 [online]. https://www.forbes.com/sites/ madhukarpai/2020/03/17/covid-19-and-tuberculosis-we-need-a-damagecontrol-plan/. Accessed 15 June 2020

Phelan JC, Link BG (2015) Is racism a fundamental cause of inequalities in health? Annu Rev Sociol 41:311-330. https://doi.org/10.1146/annurev-soc-073014112305

Pramesh CS, Badwe RA (2020) Cancer management in India during Covid-19. New Engl J Med 382(20):e61. https://doi.org/10.1056/NEJMc2011595

Public Health England (2020) Disparities in the risk and outcomes of COVID-19. Public Health England, London

Reuters (2020) UK Lawmakers to Probe Cancer Care Balance with COVID-19 Battle. Reuters, April 23, 2020 [online]. https://www.reuters.com/article/us-healthcoronavirus-britain-committee-idUSKCN22510. Accessed 15 June 2020

Rose N, Manning N, Bentall R, Bhui K, Burgess R, Carr S, Cornish F, Devakumar D, Dowd JB, Ecks S, Faulkner A(2020) The social underpinnings of mental distress in the time of COVID-19-time for urgent action Wellcome Open Res 5:166. https://doi.org/10.12688/wellcomeopenres. 16123.1

Rosenbaum L (2020) The untold toll-the pandemic's effects on patients without Covid-19. New Engl J Med 382(24):2368-2371. https://doi.org/10.1056/ NEJMms2009984

Sitrin M, Colectiva Sembrar (2020) Pandemic solidarity: mutual aid during the Covid-19 crisis. Pluto Press, London

Spiegel JM, Breilh J, Yassi A (2015) Why language matters: insights and challenges in applying a social determination of health approach in a North-South collaborative research program. Glob Health 11(9). https://doi.org/10.1186/ s12992-015-0091-2

Stuckler D, Reeves A, Loopstra R, Karanikolos M, McKee M (2017) Austerity and health: the impact in the UK and Europe. Eur J Public Health 27 (suppl_4):18-21. https://doi.org/10.1093/eurpub/ckx167

The WHO-UNICEF- Lancet Commissioners (2020) After COVID-19, a future for the world's children? Lancet 396(10247):298-300. https://doi.org/10.1016/ S0140-6736(20)31481-1

Thomson S, Figueras J, Evetovits T, Jowett M, Mladovsky P, Maresso A, Cylus J, Karanikolos M, Kluge H (2015) Economic crisis, health systems and health in
Europe: impact and implications for policy. WHO Regional Office for Europe, Copenhagen

United Nations (2020) Policy brief: education during COVID-19 and beyond. United Nations, New York

Van Dorn A, Cooney RE, Sabin ML (2020) COVID-19 exacerbating inequalities in. Lancet 395(10232):1243

Wang J, Xu C, Wong YK, He Y, Adegnika A, Kremsner P, Agnandji S et al. (2020) Preparedness is essential for malaria-endemic regions during the COVID-19 pandemic. Lancet 395(10230):1094-96. https://doi.org/10.1016/S0140-6736 (20)30561-4

Wenham C, Smith J, Morgan R (2020) COVID-19: the gendered impacts of the outbreak. Lancet 395(10227):846-48. https://doi.org/10.1016/S0140-6736(20) 30526-2

Werner F, Lammertyn M (2020) In Brazil's shadow, laid-back Uruguay curbs COVID-19. Reuters, May 23, 2020 [online] Available at https://uk.reuters. com/article/us-health-coronavirus-uruguay/in-brazils-shadow-laid-backuruguay-curbs-covid-19-idUKKBN2340EG. Accessed 23 May 2020

WHO (2013) Handbook on health inequality monitoring with a special focus on low- and middle-income countries. World Health Organization, Geneva

WHO (2020a) WHO urges countries not to let COVID-19 eclipse other health issues. World Health Organization, April 23, 2020. https://www.afro.who.int/ news/who-urges-countries-not-let-covid-19-eclipse-other-health-issues. Accessed 5 May 2020

WHO (2020b) WHO urges countries to move quickly to save lives from malaria in sub-Saharan Africa. World Health Organization, April 23, 2020. https://www. who.int/news-room/detail/23-04-2020-who-urges-countries-to-movequickly-to-save-lives-from-malaria-in-sub-saharan-africa Accessed 5 May 2020

Williams JS, Walker RJ, Egede LE (2016) Achieving equity in an evolving healthcare system: opportunities and challenges. Am J Med Sci 351(1):33-43. https://doi.org/10.1016/j.amjms.2015.10.012

\section{Acknowledgements}

This research was funded by the National Institute for Health Research (NIHR) Global Health Research Unit on Health System Strengthening in Sub-Saharan Africa, King's College London (GHRU 16/136/54) using UK aid from the UK Government to support global health research; and in part by a grant from Wellcome Trust (Ref. 204939/Z/16/Z: ZSSN: Sexual and Reproductive Health, Rights, and Justice). The views expressed in this publication are those of the authors.

\section{Competing interests}

The authors declare no competing interests.

\section{Additional information}

Correspondence and requests for materials should be addressed to N.J.

Reprints and permission information is available at http://www.nature.com/reprints

Publisher's note Springer Nature remains neutral with regard to jurisdictional claims in published maps and institutional affiliations.

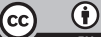

Open Access This article is licensed under a Creative Commons Attribution 4.0 International License, which permits use, sharing, adaptation, distribution and reproduction in any medium or format, as long as you give appropriate credit to the original author(s) and the source, provide a link to the Creative Commons license, and indicate if changes were made. The images or other third party material in this article are included in the article's Creative Commons license, unles indicated otherwise in a credit line to the material. If material is not included in the article's Creative Commons license and your intended use is not permitted by statutory regulation or exceeds the permitted use, you will need to obtain permission directly from the copyright holder. To view a copy of this license, visit http://creativecommons.org/ licenses/by/4.0/.

(C) The Author(s) 2021 